\title{
SER COMPAÑERAS O SER AMIGAS EN UN BACHILLERATO MEXICANO: PRÁCTICAS SITUADAS Y GÉNERO
}

\author{
María Kenia Porras Oropeza y Claudia Lucy Saucedo Ramos \\ UNAM \\ México
}

\begin{abstract}
RESUMEN
En la presente investigación se analizó la delimitación que hacen las estudiantes de bachillerato para indicar quiénes son sus compañeras y quiénes sus amigas, y su importancia en las rutinas y actividades en el bachillerato. A partir de la psicología sociocultural y la perspectiva de género feminista se elaboró un diseño que incluyó la observación en el aula y la realización de cinco entrevistas cualitativas individuales y 10 grupales con mujeres estudiantes de quinto y sexto semestre de bachillerato público mexicano. Se identificaron los contextos situados de práctica, y las actividades en las cuales las estudiantes participan como compañeras o amigas en que el género desempeñaba un papel central. Se encontró que tanto el compañerismo como la amistad eran valorados de manera positiva por las estudiantes y que en la amistad despliegan prácticas con una fuerte empatía e intimidad que les permite integrarse como mujeres, estudiantes y jóvenes en el bachillerato. Se discute que en el compañerismo y la amistad las estudiantes muestran habilidades para conseguir interrelaciones de respeto, convivencia, apoyo y sororidad que incluyen el reconocimiento de autoridad femenina y el acompañamiento corporal.
\end{abstract}

Palabras Clave:

estudiantes, bachillerato, amistad, compañerismo, género.

\section{TO BE COMPANIONS OR BE FRIENDS IN MEXICAN HIGH SCHOOL: SITUATED PRACTICES AND GENDER}

\begin{abstract}
The research approached female high school students to analyze the distinction they make between whom they considered to be their "companions", or their "friends" and the importance of this distinction for routines and activities in the school context. A methodological design was developed, based on an approach that combines sociocultural psychology and the feminist gender perspective. It included classroom observation and 15 qualitative interviews ( 5 individuals and 10 groups) with female students of the fifth and sixth semester in a public school in Mexico. The situated contexts of practice were identified, as well as the activities in which the students achieved interrelationships of companionship or friendship in which gender played a central role. It was found that while both companionship and friendship were valued positively by the students, the case of friendship implies practices with a strong empathy and intimacy that allowed them to define themselves as women, students and young people in the school environment. It is argued that, in their companionship and friendship relations, students show their abilities toachieveinterrelations of respect, coexistence, support and sorority (recognition of female authority and corporal accompaniment) as young women.
\end{abstract}

Keywords:

students, high school, friendship, companionship, gender.

Bitácora del Artículo:

| Recibido: 29 de Octubre de 2018 | Aceptado: 4 Abril de 2019 | Publicado en línea: Julio - Diciembre de 2019 | 


\title{
SER COMPAÑERAS O SER AMIGAS EN UN BACHILLERATO MEXICANO: PRÁCTICAS SITUADAS Y GÉNERO
}

\author{
María Kenia Porras Oropeza y Claudia Lucy Saucedo Ramos \\ UNAM \\ México
}

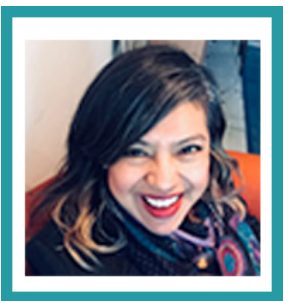

María Kenia Porras Oropeza

FES-Iztacala, UNAM

Correo: keniaporras@gmail.com

Doctorante en Psicología Educativa y del Desarrollo en el Programa de Maestría y Doctorado de la UNAM. Profesora de asignatura definitiva en la FES Iztacala, carrera de Psicología.

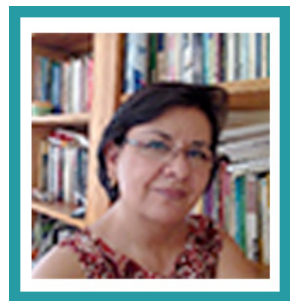

Claudia Lucy Saucedo Ramos FES-Iztacala, UNAM

Correo: saucedor@unam.mx

Doctora en investigaciones educativas. Profesor titular en la FES Iztacala, carrera de Psicología.

Ver más...

Ver más...

\section{CONTRIBUCIÓN DE LOS AUtORES}

Se atribuye a las autoras la responsabilidad única sobre el trabajar al concibir, desarrollar y coordinar el proyecto de investigación.

\section{AGRADECIMIENTOS}

Este manuscrito deriva de la investigación doctoral en el Programa de Maestría y Doctorado en Psicología de la UNAM que realiza María Kenia Porras Oropeza, quien contó con una beca nacional para efectuar estudios de doctorado otorgada por el Programa de Apoyos para la Superación del Personal Académico (PASPA) de la Dirección General de Asuntos del Personal Académico (DGAPA) de la UNAM.

\section{DATOS DE FILIACIÓN DE LAS AUTORAS}

María Kenia Porras Oropeza, FES-Iztacala, UNAM | Claudia Lucy Saucedo Ramos, ES-Iztacala, UNAM

\section{(c) (i) (2) (2)}

Copyright: (c) 2019 Porras Oropeza, M.K. \& Saucedo Ramos, C.L.

Este es un artículo de acceso abierto distribuido bajo los términos de la licencia Creative Commons Reconocimiento-NoComercial 4.0 Internacional, por lo que su contenido gráfico y escrito se puede compartir, copiar y redistribuir total o parcialmente sin necesidad de permiso expreso de sus autoras con la única condición de que no se puede usar con fines directamente comerciales y los términos legales de cualquier trabajo derivado deben ser los mismos que se expresan en la presente declaración. La única condición es que se cite la fuente con referencia a la Revista Digital Internacional de Psicología y Ciencia Social y a sus autoras. 


\section{TABLA DE CONTENIDO}

INTRODUCCIÓN

MÉTODO

Participantes, 35

Materiales, 35

Procedimiento, 36

Mediciones, 36

Análisis, 36

Resultados, 36

Discusión

CONCLUSIONES

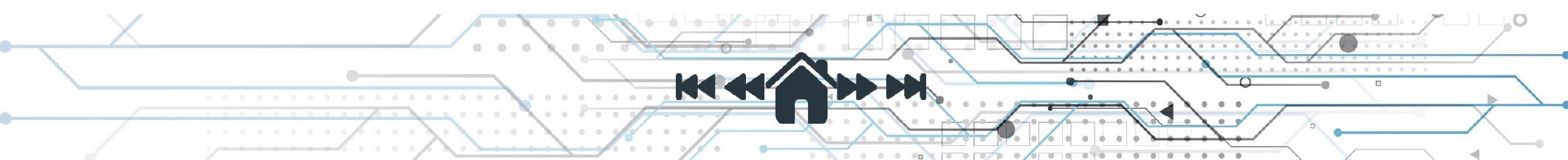




\section{INTRODUCCIÓN}

$\mathrm{E}$ n múltiples sociedades durante la infancia y la adolescencia se pasa una buena cantidad de tiempo entre pares, ya sea en guarderías, escuelas, la calle o centros de recreo. Las relaciones con otros de la misma edad tienen un impacto positivo en sus procesos de desarrollo, en lo relacionado con habilidades lingüísticas, de juego, de comunicación, de comprensión y empatía. En dichas relaciones es posible que los lazos se estrechen y en la infancia y adolescencia decidan que alguien es más que una compañía de juego y pasa a ser una amistad especial. La amistad es un tipo de relación elegida que se sostiene a lo largo del tiempo gracias al esfuerzo de quienes la alimentan, que desempeña diversas funciones en el desarrollo psicosocial de cada amistad y les permite integrarse, aprender y participar en contextos sociales por medio de grupos. Es muy difícil en la infancia o adolescencia permanecer sin dificultades al no tener amistades en la escuela. Tener amistades, aunque sólo sea una, permite integrarse a las múltiples actividades cotidianas y disfrutar del día a día.

De acuerdo con Martínez (2013), las amistades favorecen que los y las estudiantes aprendan actitudes, valores y todo tipo de información relativa al contexto en que viven; también les ayuda a percibir los puntos de vista de los demás, es decir, a ser empáticos; sus procesos de identidad y autoconcepto se retroalimentan a partir de la comparación y la información que reciben de sus amistades, y por último, logran desarrollar habilidades sociales complejas. Para Casper y Card (2010) la amistad tiene componentes importantes: interdependencia, apoyo, cuidado, intimidad, comprensión mutua, proximidad, similitudes, confianza y atracción, entre otros. A su vez, López, Rivera y Reyes (2007) afirman que las relaciones de amistad cambian con el tiempo y que los participantes tienen que hacer esfuerzos de tipo conductual, cognitivo y emocional para afrontar la naturaleza dinámica de las relaciones interpersonales.

Esto es así no sólo porque en la niñez y en la adolescencia (aunque también en la vida adulta) las personas se enfrentan a cambios a lo largo del tiempo (en relación a sus preferencias, posturas, elecciones y desarrollo de nuevas habilidades). Por ejemplo, Ibarra y Jacobo (2017) analizan que los niños hasta antes de los 12 años identifican a los demás en su escuela como amistades, y es hasta la secundaria, y aún más en la preparatoria, que los adolescentes y los jóvenes se empeñan en diferenciar a las amistades de los y las que consideran sólo como compañeras. Durante el desarrollo psicosocial se logran objetivos de identificación con los otros y procesos de selectividad sustentados en un Yo más claro.

La investigación sobre la importancia de las amistades en la vida de los niños, niñas y adolescentes es amplia y ha considerado el papel de la misma en distintos campos de actuación, sólo por mencionar algunos: diferencias en la calidad de las relaciones de amistad en función del género (Mathur y Berndt, 2006), la amistad y su influencia en el rendimiento académico (Pantoja, 2013), la ruptura de la amistad y su efecto en los adolescentes (López, Rivera y Reyes, 2007), la importancia de las amistades en conductas desviadas de la norma social (Moreira, Sánchez y Mirón, 2010), la función de las amistades en redes sociales (Bohórquez y Rodríguez, 2014) y la importancia de la vida juvenil en el bachillerato por medio de las amistades y el compañerismo (Hernández, 2012).

Por otro lado, el estudio del compañerismo entre el estudiantado en la escuela implica el despliegue de prácticas complejas vinculadas a la sociabilidad y la afectividad tanto de los hombres como de las mujeres que participan en ellas. La mayoría de las veces se caracterizan desde la perspectiva de las personas investigadoras y desde miradas adultocéntricas, es decir, en formas que consagran privilegios para los adultos sobre los adolescentes y jóvenes, basadas en la diferencia de edad y superioridad de la condición adulta (UNICEF, 2013). En este trabajo las prácticas son consideras como una configuración de acciones, actividades, formas de dialogar y de construir significados y sentidos, situadas en espacio-tiempo-lugar de las relaciones interpersonales, es decir, son relacionales.

En el caso de las mujeres, Mejía y Weiss (2011) encontraron que las prácticas relacionales "femeninas" más importantes entre las estudiantes mujeres de secundaria eran la amistad y el compañerismo. Se indica que la rivalidad por los estudiantes hombres destacó como uno de los motivos por los que las estudiantes mujeres pelean con sus compañeras y amigas en la escuela, por lo que el compañerismo y la amistad en la escuela son consideradas como prácticas en la construcción de "la identidad femenina adolescente", que aún están orientadas por las regulaciones de género.

Respecto a la presencia y participación de las mujeres en la escuela, Tomasini y Bertarelli (2014) indican que las mujeres jóvenes asumen posicionamientos genéricos diversos en la escuela que pueden variar contextualmente y que son contingentes a las demandas de identidad que emergen en los distintos escenarios de in- 
teracción, por lo que plantean el contexto escolar como un lugar para la producción de identidades de género.

En el campo de investigación de las sociabilidades, Paulín (2015) analizó las prácticas relacionales y los procesos de reconocimiento entre estudiantes de escuela media, y encontró que entre las estudiantes existen códigos relacionales, en los que la corporalidad adquiere centralidad como recurso tanto para conocerse como y para definir si una relación es de compañerismo o amistad. Mediante la corporalidad las estudiantes indican el lugar en que una estudiante posiciona a otra ante su mirada (como "rebajarla"), que puede implicar rechazo y exclusión.

En otra investigación, Tomasini (2015a) analizó las feminidades juveniles y el uso del cuerpo en estudiantes de escuela secundaria. Encontró que las estudiantes construyen determinadas estéticas y prácticas corporales por medio de la cuales se identifican, diferencian y jerarquizan entre ellas. Así, el cuerpo entre las mujeres estudiantes adquiere centralidad en la sociabilidad escolar porque es el medio privilegiado de reconocimiento de las identidades, sobre todo las de género. Indica que en los cuerpos se inscriben los contactos físicos, las expresiones de afecto, las posturas corporales junto con la vestimenta, el uso de accesorios y el peinado.

Recientemente el compañerismo entre las mujeres como tema de estudio se ha extendido del contexto escolar a otros ámbitos, como el activismo social para la comprensión y transformación social de las relaciones entre las mujeres. De esta manera, para Korol (2015) ser compañeras se entiende desde los feminismos como un conjunto de prácticas caracterizadas por el acompañamiento para liberarse de las violencias que las rodean; esto desde los conocimientos que tienen unas y otras para enfrentarlas. Así, las compañeras feministas se ayudan a salir del lugar de víctimas para colocarse a sí mismas y a otras mujeres como sujetos con historia, como mujeres activas frente al heteropatriarcado, apoyadas en la solidaridad y el fortalecimiento entre ellas en experiencias compartidas.

Respecto a la amistad, Ramírez (2014) la considera como una base para nuevas formas de moralidad social, y cada vez adquiere mayor relevancia tanto social como personalmente porque, por un lado, se ha demostrado que en estas relaciones se reproducen y generan diversos fenómenos sociales, y que, por otro lado, la amistad tiene mayor relevancia en la vida de las personas adultas y no sólo en la etapa de adolescencia donde se le ha estudiado con más frecuencia.

Para Gaviola (2015) la amistad entre las mujeres ha adquirido una dimensión feminista para enfrentar la misoginia internalizada que, con frecuencia, las mujeres tendemos a rechazar, devaluar, negar u odiar a otras mujeres que son, piensan y actúan fuera de los códigos de la feminidad impuesta, es decir, a las mujeres que cuestionan y viven con independencia y autonomía. Además, dicha autora propone la deconstrucción de las relaciones de amistad entre mujeres para sortear las envidias, rivalidades y competencia en los discursos de género por medio de relaciones transparentes y honestas sin subsumir el pensamiento propio o de la otra.

Así, las mujeres participan en prácticas relacionales en la escuela como estudiantes, como jóvenes, como amigas, como compañeras. Se enfrentan en el contexto escolar a demandas académicas, de sociabilidad y de género en ese momento de su vida. Al respecto, Lagarde (2012) propone la participación de las mujeres en relaciones sororas o sororales para desmantelar la naturalización de las relaciones conflictivas entre las mujeres, como la enemistad y la rivalidad. Las define como un conjunto de prácticas sociales entre mujeres que implican un posicionamiento ético y político para enfrentar el sexismo y sus manifestaciones (androcentrismo, machismo, homofobia y misoginia) entre las mujeres.

Las relaciones sororas o sororales se enfocan en la valoración de las mujeres y el apoyo central entre ellas, por lo que están libres de androcentrismo. Promueven la resignificación de la fuerza, la valentía, el enojo y corajes como derechos de las mujeres, así como el replanteamiento de las mujeres como expertas y especialistas en el cuidado de sí mismas y de otras mujeres, por lo que están exentas de machismo. Además, están libres de misoginia al promover la valoración positiva de las mujeres en el mundo social y cultural. También en las relaciones sororales el daño, la marginación, el maltrato, la hostilidad, la agresividad son considerados como aprendizajes sociales culturales, no naturales.

Las relaciones sororas o sororales están abiertas a la comprensión de la sexualidad de las mujeres, al derecho de las mujeres a decidir su vida sexual, en el erotismo y afectividad con hombres o mujeres, al tipo de encuentros o relaciones que desean establecer, así como a decisiones de la vida reproductiva (maternidad, anticoncepción, interrupción del embarazo, etcétera), por lo que están libres de homofobia (Lagarde, 2012).

En la presente investigación se analizan las prácticas de amistad y compañerismo que estudiantes mujeres de nivel medio superior despliegan para encontrar su lugar en la escuela, tanto en un plano afectivo como social en las relaciones que establecen entre ellas. El objetivo es identificar las delimitaciones que realizaron para indicar quiénes eran sus compañeras y quiénes sus amigas, así como la importancia de cada una en las distintas rutinas y actividades que tenían en la escuela. 
Desde un enfoque sociocultural se visualiza de modo analítico a las estudiantes como siempre situadas en contextos sociales de práctica. Es decir, espacios, lugares, tiempos, que son co-construidos por las personas en la organización escolar en que participan. En dichos contextos cada persona toma una posición social (como alumno, como docente, como empleado, etcétera) y desde ahí negocia formas de participación que deben responder a las demandas de actuación de la escuela, pero que también dan cuenta de sus posturas personales, esto es, los puntos de vista que adoptan sobre su compleja práctica social en las ubicaciones (lugares) en que participan y transitan (Dreier, 1997). El conjunto de actividades que se desarrolla en una escuela, con sus recurrencias, historias de articulación, eventos con significado y lógicas de sentido, se constituyen en prácticas sociales según las cuales cada persona obtiene un marco de actuación y orientación del Yo.

De esta manera, ser persona es el resultado de las diversas participaciones que cada quien tiene en distintos contextos de práctica social (la escuela, la familia, la comunidad, las tecnologías de información y comunicación) y la indisoluble relación entre el hacer-pensar-sentir que da paso a la identidad unificada en un relato, en un yo que es múltiple, pero que a la vez se presenta a sí mismo, actúa y se narra con coherencia (Bruner, 1990).

Dada la importancia del desarrollo psicosocial de las estudiantes, se analizan a lo largo del texto los componentes de amistad y compañerismo entre mujeres en la escuela preparatoria, es decir, cómo las estudiantes asumían posturas personales para discernir quién era su amiga y quién su compañera, para así pensar y vivir los lazos interpersonales que les permitieran decidir su lugar como mujeres en la escuela y en las relaciones que establecen entre ellas.

Por lo anterior, la investigación también se apoya en la perspectiva de género feminista (Martínez, 2012) que estudia las condiciones y situaciones en las que el género implica una participación personal, social y política en los distintos contextos. Para este trabajo se retoman las nociones de sororidad como una forma de empatía entre mujeres como iguales y distintas en el camino a la democracia genérica (Lagarde, 2012), affidamento, es decir, el reconocimiento de la autoridad femenina (Cigarini, 2000) y acuerpamiento, esto es, el acompañamiento corporal como acción de resistencia personal y colectiva para apoyarse entre mujeres en situaciones que lo requieren (Cabnal, 2018).

Por medio de un diseño cualitativo, en el presente estudio se informa de la experiencia de las estudiantes en el bachillerato como mujeres y jóvenes desde su voz, para lograr una comprensión profunda del papel del género en las prácticas relacionales en que participan y en su posible transformación social en el terreno educativo.

\section{Método}

\section{Participantes}

En la investigación participaron de manera voluntaria 61 mujeres estudiantes con edad promedio de 17 años, de quinto y sexto semestre de bachillerato. Pertenecían a tres grupos conformados con 18, 22 y 21 mujeres cada uno, del turno matutino del $\mathrm{CCH}$. El muestreo fue intencional no probabilístico (Hernández, Fernández y Baptista, 2010). Para el caso de las mujeres estudiantes menores de edad se tuvo el consentimiento de los padres, madres o tutores(as) legales para que participaran en la investigación, y en el caso de las estudiantes mayores de edad fueron ellas quienes firmaron el consentimiento.

Aunque no se incluyen datos acerca de la participación de los estudiantes hombres de los tres grupos referidos, se tuvo su consentimiento o el de sus padres, madres o personas tutoras en los casos en que eran menores de edad.

Todas las estudiantes participantes eran solteras al momento de la investigación. Provenían de diferentes alcaldías de la Ciudad de México (Iztacalco, Iztapalapa y Cuauhtémoc) o de algún municipio del Estado de México (Nezahualcóyotl, Chimalhuacán, Chalco y Chicoloapan) que colinda con el $\mathrm{CCH}$. El tamaño de la muestra dependió del punto de saturación de los datos. Las entrevistas se consideraron suficientes cuando el contenido de los ejes de indagación se repitió en varias de ellas. En los resultados presentados se cambiaron los nombres de las estudiantes participantes para garantizar el anonimato en los fragmentos de transcripción presentados. Se les comunicó que la información obtenida durante la investigación se podría hacer pública evitando detalles con las que las pudieran identificar.

\section{Materiales}

Se creó una guía de observación (rutinas, actividades recurrentes, historias compartidas, eventos significativos y sentidos construidos) y una guía de entrevista con seis ejes de indagación a partir de las observaciones hechas en el aula y la revisión bibliográfica. Los ejes fueron: 1) compañerismo y amistad-enemistad; 2) cuerpo y feminidades; 3) relaciones con los hombres; 4) formas de violencia; 5) expresiones de sororidad (Lagarde, 2012), y 6) dinámicas de poder. En el presente artículo nos enfoca-

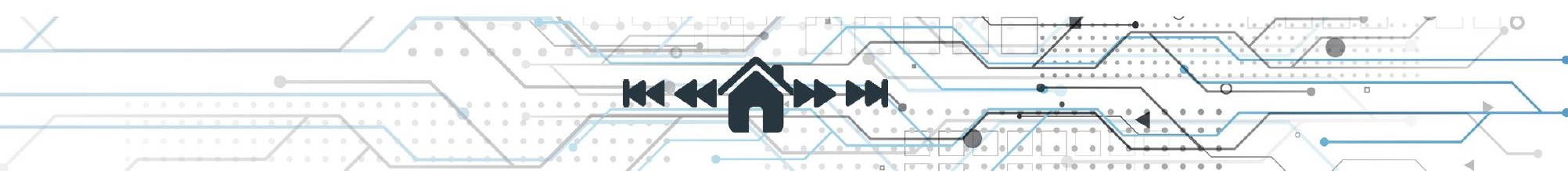


mos en el primer eje, pero es importante aclarar que el mismo formó parte de una investigación más amplia.

\section{Procedimiento}

La investigación se efectuó en un Colegio de Ciencias y Humanidades $(\mathrm{CCH})$ de la UNAM. El estudio tuvo una duración de ocho meses (de septiembre de 2016 a mayo de 2017). El trabajo de campo inició con visitas a la coordinación de psicopedagogía del plantel para conocer las características del estudiantado. Después fueron elegidos los grupos que participarían por sugerencia de la coordinación de psicopedagogía, por el horario y por la disponibilidad del profesor a cargo para observar. En seguida la investigadora/observadora fue presentada a cada grupo para iniciar la observación participante y se dio paso a la recolección de datos para identificar rutinas, actividades recurrentes, historias compartidas, eventos significativos y sentidos construidos en el aula por alumnas pertenecientes a tres grupos - cada uno en promedio de 52 alumnos(as) - durante 41 clases (72 horas), todo ello con la intención de comprender cómo se entrelazan en la vida social los sentidos, los significados y las prácticas en el contexto escolar (Guzmán, 2014). La primera autora del presente texto fue quien hizo el trabajo de campo y para ello elaboró un diario durante las clases, mismo que era ampliado al finalizar la observación cada día. También se hizo un registro visual de 1,068 imágenes tomadas durante las clases, las cuales les eran mostradas a los y las estudiantes para decidir si querían que fueran parte de la investigación o borradas de inmediato.

Al finalizar el periodo de observación, se invitó a las estudiantes de los tres grupos a participar de manera voluntaria en entrevistas empáticas, que fue el segundo método para la recolección de datos. En total participaron en 15 entrevistas (cinco individuales y 10 grupales). A decir de Fontana y Frey (2015), este tipo de entrevistas implica procesos que involucran a las personas (situadas contextual e históricamente) en intercambios que representan un esfuerzo colaborativo a favor de las personas o los grupos en estudio; en este caso las mujeres estudiantes. Las entrevistas individuales y grupales tuvieron una duración de entre 50 y 108 minutos, fueron videograbadas y se informó a las participantes que su contenido sería tratado con discreción y sólo estaría disponible para la persona que haría las transcripciones y para el análisis de los datos durante la investigación.

\section{Mediciones}

Se elaboró un diseño cualitativo para la recolección y análisis de los datos, porque se buscó - a partir de la observación participativa y colaborativa - recuperar las experiencias de las estudiantes en su contexto de participación (Hernández, Fernández y Baptista, 2010) y facilitar que tomaran la palabra mediante el diálogo verbal (entre ellas y con la persona investigadora) respecto a las prácticas de compañerismo y amistad que despliegan en el ámbito escolar.

\section{Análisis}

Las entrevistas fueron videograbadas, transcritas y escuchadas varias veces para la selección y análisis de extractos por acumulación de circunstancias particulares pero similares (Gibbs, 2012). En el análisis se incluyen datos del diario de campo, que fue leído y ampliado al finalizar cada observación, y del registro visual de las observaciones en el aula. Para los fines del presente artículo, como se ha señalado, sólo se consideraron los temas de compañerismo y amistad, que corresponde al primer eje de indagación (compañerismo y amistad-enemistad). En seguida se presentan los resultados de dicho eje.

\section{Resultados}

El estudio tuvo una duración de ocho meses (de septiembre de 2016 a mayo de 2017). En ese periodo se hizo la observación de los grupos en las aulas y las entrevistas. A partir de los textos del diario de campo y de las transcripciones se hizo el análisis y se obtuvieron los resultados que en seguida se presentan de las prácticas de compañerismo y amistad entre las estudiantes de bachillerato, su lugar como mujeres a partir de ellas y la importancia para su desarrollo psicosocial en el ámbito escolar.

\section{Prácticas de compañerismo}

Al inicio de cada año escolar, el estudiantado es asignado a un grupo específico. En el primer año son asignados a un grupo de manera aleatoria y permanecen en él durante dos semestres (primero y segundo). Para el segundo año son asignados de manera aleatoria a un grupo distinto al del primer año, y permanecen en él también por dos semestres (tercero y cuarto). En el tercer año, los y las estudiantes eligen las asignaturas que cursarán, de acuerdo con la carrera de licenciatura que desean estudiar, y son distribuidos en los grupos que se establezcan de esa materia, por lo que en lugar de ser parte de un grupo están en tantos grupos como asignaturas cursan. De este modo, en los dos semestres del tercer año (quinto y sexto) pueden o no participan en las clases con compañeras y compañeros que conocieron en semestres anteriores. De este modo, las prácticas de compañerismo que despliegan las estudiantes de bachillerato están situadas en la estructura y organización escolar, y se ubican en el aula durante las clases, fuera de ellas en algunos espacios en la escuela (pasillos, áreas comunes, biblioteca, etcétera) y fuera de 
la escuela (centros comerciales cercanos, lugares para consumir alcohol, museos o teatros que visitan por las demandas escolares, etcétera). En la tabla 1 se enlistan los contextos y las actividades que las estudiantes dijeron que compartían con sus compañeras de escuela.

Tabla 1.

Contextos y actividades en que se establecen las prácticas de compañerismo.

Contexto Prácticas de compañerismo

En el aula antes de clases Platicar sin detalles de asuntos personales.

Pasarse en ocasiones la tarea.

Vender y/o comprar dulces y botanas.

Conformar equipos de trabajo.

Hacer trabajos escolares.

En el aula durante clases Exponer juntas un tema. Preguntarse y opinar entre ellas del tema de la clase. Ponerse de acuerdo para hacer algún trabajo.

Ponerse de acuerdo para hacer trabajos. Acordar por WhatsApp tiempos de trabajo.

Fuera del aula Hacer trabajos en la biblioteca.

Competir en concursos (ofrendas, disfraces y piñatas).

Encontrarse en visitas

Fuera de la escuela escolares (museos, teatros, etcétera).

Como se observa en la tabla 1, para las estudiantes el compañerismo se expresa en un conjunto de actividades que tienen lugar en el aula o fuera de ella, ya sea en tiempos de trabajo o en tiempos para ponerse de acuerdo para desarrollar alguna actividad académica. Destaca que mediante el compañerismo las estudiantes comparten espacios, temas de conversación, objetivos para el desempeño académico y actividades, entre otros; y aunque expresaron ser cuidadosas en su manera de tratar a las compañeras para no generar conflictos, no por ello tienen una relación de intimidad y afecto con ellas.
En la siguiente transcripción de entrevista, una estudiante de sexto semestre indica la diferencia entre ser compañera y amiga en la clase de Psicología.

Investigadora: Ahí en el salón, donde hago la
observación. ¿Tienes alguna amiga?
Thalía: Compañera.
Investigadora: ¿Cuál sería para ti la diferencia
entre ser amiga y ser compañera?
Thalía: Pues, una amistad creo que conoces a
la persona como es. Sabes lo que le gusta y lo
que no, y pues te cuenta aspectos de su vida,
de su casa, de lo que le sucede, cómo se siente,
o no sé, algo así como más personal. Y pues
compañerismo es sólo hablar con ellas, pero
no conocerlas tan a fondo sino sólo en clase;
hablar más que nada.
Investigadora: Entonces las compañeras son
así, compañeras nada más en clase.
Thalía: Ya si te las encuentras en los pasillos
dices: hola-adiós.

Para Thalía ser compañeras supone conocer a las estudiantes de su salón, entablar con ellas conversaciones pero no "a fondo". Como señalan Casper y Card (2010), no existe una intimidad emocional que suponga la confianza para tener una proximidad y comprensión mutua. Al profundizar con Thalía en el significado de la diferencia, enfatizó que la amistad implica acciones como mostrarse abiertamente, conocer los gustos de la otra persona, platicar a fondo sobre temas como la familia, sus vivencias y sus sentimientos. De esta manera, platicar en clase de algunos aspectos de su vida personal (como la familia, las amistades o sus relaciones de pareja), sin entrar en detalles, es para las estudiantes una práctica que despliegan con sus compañeras en la que se observan y deciden la cantidad y profundidad de la información que comparten de sí mismas y sus vivencias.

La tabla 1 también muestra que ser compañeras supone no sólo saludarse, sino participar juntas en diversas actividades: compartir las mesas durante las clases, platicar de la materia o tareas que les hayan dejado, vender y/o comprar dulces. Esto incluso puede ocurrir sin que cada estudiante conozca los nombres de todas las compañeras del grupo. Así, por ejemplo, la "chica de los dulces", es una compañera más, y ante ello una estudiante refiere que es difícil aprenderse todos los nombres por la cantidad de grupos en que cursan el quinto y el sexto semestre.

Celia: Yo digo que es difícil porque... así como que ya pensándolo bien... amistad-amistad ya 
ahorita quinto y sexto, es muy difícil. Primero porque ya te tienes que enfocar en lo que... a lo que vas... Y ya ponerte las pilas, porque ya es lo último. Primero eso, y luego nada más a clase... Por ejemplo, a mí se me dificulta en eso de los nombres, o sea, si de por sí es difícil cuando llevas dos semestres con esas personas, pues ahora que nada más los ves de un ratito, ni como para quedarte a platicar, ni así, porque no comparten mucho tiempo con uno.

Es necesario recordar, de acuerdo con López, Rivera y Reyes (2007), que las relaciones interpersonales son dinámicas y cambiantes a lo largo del tiempo, por lo que Celia se refiere a la dificultad de aprenderse los nombres de todas las compañeras con quienes tiene que interactuar en su paso por distintos grupos. Al mismo tiempo, la ausencia de similitudes y de objetivos comunes coloca a Celia en la decisión de no identificar a sus compañeras como amigas.

Empero, el que las estudiantes no se identifiquen como amigas sino como compañeras, no es algo que les moleste. Este posicionamiento les permite delimitar los tipos de relaciones interpersonales que tienen.

Investigadora: ¿Ustedes se consideran amigas?

(Silencio.)

Alexis: Ehhh. No.

(Ariadna, Mirna, Celia mueven la cabeza diciendo que no.)

Investigadora: ¿Cómo se consideran ustedes?

Ariadna: Compañeras de clase.

Celia: Sí, compañeras.

Investigadora: ¿Tienen amigas aquí en el $\mathrm{CCH}$ ?

(En diferentes momentos todas responden que sí.)

Mirna: En el CCH sí.

(Risas.)

Investigadora: Platíquenme... ¿En qué es diferente ser amigas que compañeras?

Marisela: La forma de convivir o de lo que le platicas a la otra persona porque, por ejemplo, aquí nosotras hablamos más de la materia como... de algunas cositas en común que surgen en la plática; pero en la amistad ya cuentas más lo personal. Le tienes más confianza a la otra persona. Tal vez sí podemos contarle un poco, pero no tanto ni tan profundo como con una amistad más cerca.

Daniela: Igual porque no convivimos como mucho tiempo, sólo en la clase y ya.

Las estudiantes responden sin vacilar que no son amigas; que son sólo compañeras. Ellas delimitan lo personal de lo público, de modo que lo segundo es característico del compañerismo porque favorece platicar y hacer actividades que están a la vista de todos. Mientras que la intimidad y la cercanía emocional queda reservado para la amistad. Es necesario destacar que se trata de un compañerismo situado, porque se construye en el contexto del aula y de la escuela en la que cursan su bachillerato, y responde a demandas particulares de la organización escolar, porque en otras escuelas la organización por grupos se mantiene durante los tres años que dura el bachillerato. De este modo, cuando ellas utilizan la noción de compañera aluden a las otras estudiantes que son parte del grupo escolar en que están, que no es lo mismo si se tratara de una actividad laboral, política o comunitaria.

Para las estudiantes ser compañeras también implica otras prácticas, como competir entre ellas. Así, una estudiante comenta que esa práctica se efectúa sólo entre compañeras, porque entre amigas eso no ocurre por el vínculo afectivo que existe.

\section{Ana: Pues una compañera siempre te va a ver para cosas de la tarea. Y a una amiga pues... Pues de la tarea, de lo que te está pasando. Contarle tus problemas. Que ella te dé conse- jos, opiniones o de lo que esté sucediendo. $Y$ una compañera es nada más: "Ah, sí la tarea". Y nunca... a una compañera no le va a impor- tar si hiciste las cosas bien o no, y a una amiga sí le va a importar. \\ Flor: De una manera hay como más compe- tencias, porque no hay como ese lazo afectivo que, por ejemplo, con Ana; digo, nunca hemos competido así de: "Ah, soy más que tú". Y con una compañera yo siento que no hay como ese lazo afectivo que nos une a Ana y a mí.}

La competencia de la que hablan las estudiantes significa una diferenciación en la que establecen jerarquías en el terreno escolar y una desvinculación afectiva en lo emocional. Se colocan como amigas y valoran de manera positiva el interés que tiene una de la otra a partir del lazo afectivo que han construido, en lugar de competir entre ellas. Así, la competencia implica falta de afectividad y de interés en la situación personal de otra estudiante. 
Es importante destacar que las estudiantes todo el tiempo hicieron alusión a la dupla compañera-amiga para poder diferenciarse. En ese sentido, ambas dimensiones forman parte de un continuo de relaciones interpersonales que inicia con prácticas de compañerismo cuando se les ubica en un grupo escolar, y puede o no avanzar hacia prácticas de amistad, dependiendo de los lazos de intimidad y confianza que logren establecer. Ellas distinguen a las compañeras como personas con las que pueden compartir actividades, espacios dentro y fuera de la escuela, así como pláticas; todo esto con un carácter escolar, mas no íntimo.

Las estudiantes se encuentran todo el tiempo monitoreando quiénes son sus compañeras y quiénes son sus amigas para identificar las actividades que pueden compartir. Este trabajo supone un esfuerzo emocional, cognitivo y social, porque nos permitieron ver que se muestran cuidadosas para no confundirse a sí mismas ni confundir a las demás haciendo alusión a quién pueden considerar compañera o amiga. Así, por ejemplo, Mayte nos habló del esfuerzo que hace para distinguir a las demás.

\section{Mayte: De ahí en fuera, de lo que restó del semestre, éramos nada más Mariana y yo. $Y$ luego había otro par de amigas. Desde el pri- mer día como que... igual coincidieron y se jun- taron con nosotros. Y luego se unieron más y así. Y una como que se alejó y de ahí en fuera también la otra... Bueno, yo no las considero amigas-amigas, pero tampoco compañeras; es como que algo intermedio; no sé... [En otra parte de la entrevista se refiere a ellas como compañeras-amigas.] Y con ellas hasta ahori- ta... De hecho, acabo de estar con ellas... Igual las conozco desde el primer semestre. En gru- po hemos salido no sé, a fiestas, y si ellas dicen: "Vamos a salir o algo", le dicen a Mariana. $Y$ ella, pues [dice] "No sé, pues voy a ver si Mayte va". Si voy yo, pues dice "Vamos". Y así...}

En este fragmento de entrevista, Mayte hace un esfuerzo de diferenciación del vínculo que sostiene con otras estudiantes. Ella habla de prácticas que suponen ser "compañeras-amigas", por conocerse desde hace tiempo y salir en grupo a fiestas (contexto interrelacionado). Sin embargo, enfatiza que hay un vínculo diferente con la estudiante que considera su amiga. Así, las estudiantes participan en interacciones combinadas con otras estudiantes a las que consideran como compañeras, como amigas o en categorías que ellas construyen como ser compañera-amiga para comprender las relaciones que establecen con otras estudiantes.

La diferenciación entre compañeras y amigas también se practica en aspectos que comparten o no como la vestimenta, el gusto por cierto tipo de música, el arreglo personal y las actividades hechas fuera de la escuela. Estos contenidos que delimitan el compañerismo de la amistad también fueron analizados por Grijalva (2011) para dar cuenta tanto de la vida juvenil en las escuelas como de la configuración de sus identidades grupales e individuales.

En resumen, el espacio escolar permite que las estudiantes se encuentren con compañeras en los distintos grupos en que están inscritas cada semestre. Con algunas de ellas logran mayor afinidad al compartir actividades académicas y pláticas en temas generales; con otras ni siquiera sabrán sus nombres; sólo las reconocerán como compañeras de grupo. Si bien no asignan el mismo valor a ser compañeras que amigas, no por ello son relaciones menos importantes, porque permiten la fluidez del trabajo académico y la posibilidad de afianzarse en relaciones de género (a diferencia de si las estudiantes estuvieran en aulas con una población mayoritariamente de varones). Así, destaca la importancia de practicar relaciones interpersonales entre mujeres en las que puede existir el reconocimiento de jerarquías con las que se ofrezca respeto y posibilidades de aprender unas de otras, como señala Korol (2015), con límites afectivos para continuar identificándose como compañeras, que puede hablar, trabajar, pasar el tiempo, ponerse de acuerdo para tareas, apoyarse. Las compañeras no pasan a una dimensión afectiva íntima, pero sí tienen una función fundamental en la integración de las estudiantes al ambiente escolar y en el desarrollo de habilidades psicosociales para la interacción entre pares.

\section{Prácticas de amistad}

De acuerdo con las narraciones de las estudiantes, hablar de sus amigas conlleva construir una historia acerca de cómo se conocieron y lo que han compartido al paso del tiempo. Hay que recordar que el alumnado en el $\mathrm{CCH}$ es cambiado de grupo de un semestre a otro, de modo que las amistades que se logran al inicio pueden perder fuerza si las estudiantes no se afanan por conservarlas, o si otras amistades llegan a tener más presencia en los semestres posteriores. Así, las estudiantes hablaron con remembranzas como: "la conocí en primer semestre", "nos tocó tener dos clases juntas", "fue creciendo la confianza", "teníamos sólo compañeros, pero a mí no me caían muy bien". A diferencia de las compañeras, las amigas tienen una historia de relación, 
lo que se complementa con una dimensión de empatía, intimidad y confianza.

Hay actividades y formas de comportarse que, de acuerdo con las estudiantes, definen la amistad. En la tabla 2 se enlistan los contextos y las actividades en que se establecen las prácticas de amistad en estudiantes mujeres de un $\mathrm{CCH}$ a partir de la observación en el aula.

Tabla 2.

Prácticas de amistad en el contexto escolar.

Contexto

Prácticas de AMISTAd

Llegar juntas al aula, sentarse juntas.

Maquillarse y peinarse juntas, y opinar al respecto.

Comer juntas y compartir alimentos.

En el aula antes de clases

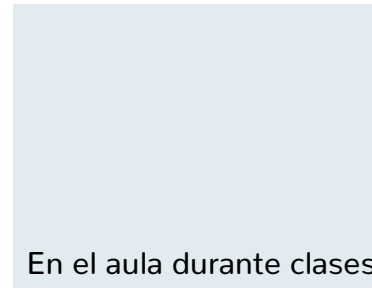

Fuera del aula
Contexto

Prácticas de AMISTAd

Hacer trabajo en casa de su amiga

Acompañarse en el camino a casa.

Fuera de la escuela

Ir al centro comercial después de la clase o si no hay clase. Ir a fiestas con amistades. Ir a tomar alcohol.

Cuidarse en "las pedas". Ir a fiestas familiares.

Las estudiantes relataron que sus amistades iniciaron cuando compartieron un grupo y ahí empezaron a realizar una labor de conocimiento y búsqueda de empatía.

Flor: Y dijimos: Yo me iba a juntar con esa chica... Entonces las dos nos sentamos juntas porque nos íbamos a juntar con la chica, pero al final la chica se cambió de grupo, y ya, pues ya nos juntamos las dos.

Investigadora: ¿Qué les llamó la atención de esa chica que dijeron "quiero que sea mi amiga o juntarme con ella"?

Flor: Se veía tranquila; es que hay más estudiantes que como que las veo y digo "se ven muy creídas". Entonces yo la vi y dije "se ve tranquila", y... considero que podía ser una... bueno, desde el punto de vista físico, pues igual se ve tranquila...

Ana: $\mathrm{mmm}$.

Investigadora: ¿Y en tú caso?

Ana: Pues igual; fue ver a la chica y dices "se ve como amigable y como de mi estilo". De cómo ella es, yo también soy... Como que te identificas.... Igual después, este, ya cuando empezó la clase, pues igual te fijas en la forma en que hace los apuntes, sus compañeros, por decir así de ella, sí hace las cosas bien o no las hace bien.

Flor: Exacto. Porque igual hay personas que como que algunas veces dices "ay, no van a hablar". Y así, yo soy de estar comentando las cosas. Hay personas que son muy cortantes y eso a mí la verdad no me agrada. Y entonces, pues esa chica se veía agradable.

Las estudiantes expusieron las estrategias que han usado en los primeros encuentros en el aula con otras estudiantes, en las que planean, calculan y llevan a la práctica acciones para acercarse a otras estudiantes e iniciar interacciones que se sostengan en el tiempo y en otras 
actividades, es decir, proyectan las consecuencias de sus acciones de acuerdo con sus necesidades e intereses futuros. Ana y Flor distinguieron componentes de la posible amiga en su apariencia y comportamiento, y reflexionaron acerca de las similitudes que podían tener con ella, como platicar, "no creerse" o ser tranquila. Casper y Card (2010) insisten en la búsqueda de similitudes por parte de los adolescentes para dotar de calidad a la amistad, mientras que Pantoja (2013) analiza cómo la amistad en la escuela no está desligada de la posibilidad de tener un buen o mal rendimiento académico.

En sus relatos, las estudiantes también destacaron la importancia de tener amigas cuando se encontraban en un grupo en el que predominaban compañeros hombres. Si bien durante la investigación también se observaron prácticas de compañerismo entre estudiantes hombres y estudiantes, así como relaciones de amistad, el objetivo analítico fue caracterizar las prácticas de amistad entre estudiantes mujeres, algo que ellas mismas valoran de modo positivo.

\section{Sara: Entonces, pues para mí la amistad es im- portante. Ser amigas y... con una chica, bue- no, a mí se me hace algo muy especial porque por lo general me junto con muchos hombres; entonces, cuando logras entablar una amistad con una mujer es... algo muy, muy especial para mí. Lo valoro demasiado. \\ Investigadora: Ok. \\ Clara: De hecho, es muy bonito porque de todo el grupo de amigos, todos son niños y somos las únicas dos niñas.}

No en todos los grupos del $\mathrm{CCH}$ sucede que haya un mayor número de estudiantes hombres, pero lo que sí se observó es que en los tres grupos en general las estudiantes buscaron consolidar sus relaciones de amistad con otras estudiantes, y en las entrevistas unas cuantas dijeron que sus mejores amigos eran "niños", es decir, hombres. La amistad para ellas fue una dimensión de encuentro de similitudes y para fomentar intimidad y confianza.

En la tabla 2 se muestra que las prácticas de amistad también ocurren en el aula antes, durante y después de las clases, así como fuera de la escuela. Las estudiantes dijeron que siempre que llegan al aula buscan el espacio que comparten con las amigas en turno para sentarse y disponer en las mesas un conjunto de artefactos culturales (Esteban, 2011), lo que se puede interpretar como parte de la geografía del aula: cuadernos, lapiceras, libros, el lunch del día, la botella de agua, la cosmetiquera con maquillaje y espejo, el teléfono celular, etcétera. Antes de que inicie la clase, las amigas invierten tiempo en el arreglo personal y en compartir experiencias de lo que aconteció el día previo; sobre todo el apoyo entre amigas es fundamental respecto al cuidado personal, la apariencia y la belleza.

Investigadora: $Y$ entre ustedes, ¿se han apoyado para ayudarle a la otra a sentirse segura de sí misma?

Ana: Bueno, nos damos consejos; porque a mí también me salen granitos, entonces era de "ponte esto, yo me puse esto. Y sí me funcionó", ¿no? Yya, así...

Flor: Pero también con Isabel, de que a veces se sentía rara por su cuerpo o así. Y pues nosotras tratábamos de decirle "no, pues te ves bien, o jay, qué guapa!".

Ana: O cuando nuestra compañera se arreglaba más, siempre se lo decíamos; como "te ves muy bien si te haces eso"... Y ella "ay, ¿sí?". Igual ellas también me decían "hoy si te arreglaste", o así...

(Risas.)

Flor: Te arreglaste...

Investigadora: ¿Cómo se sienten cuando animan a la otra a sentirse mejor consigo misma? Como esto que me platicaban de Isa.

Ana: Pues, yo siento como que le ayudamos...

Flor: Bien por ella... Eso de que se sentía insegura me hace sentir... y que veo cambios en ella me hace sentir muy, una satisfacción en poder... en decir "estoy ayudando y estoy siendo una buena amiga con ella".

El tiempo que las estudiantes dedican en el aula para el arreglo personal se complementa con las miradas entre ellas que retroalimentan la seguridad de la amiga al resaltar su belleza. Se trata de una intersubjetividad en la cual hay un mundo mental compartido (Martínez, 2011) que les permite entenderse, motivarse y posicionarse como mujeres "guapas", "bonitas", "atractivas", "mayores", etcétera. De esta manera, entrar al aula, estar en el aula, implica ejercitar su condición de género porque buscan a las amigas para sentirse apoyadas y reconocidas.

Antes y durante las clases, en el aula también se despliegan actividades de diversión, ya sea reírse por las anécdotas que se platican o por el uso del celular con el que tienen acceso a videos, memes, música, tutoriales, mensajes, etcétera. Ellas no sólo comparten las posibilidades que les dan las tecnologías de la información en el aula, sino que les permite estar en contacto frecuente 
fuera de la escuela, y como observan Bohórquez y Rodríguez (2014), los vínculos de amistad se fortalecen.

Ya se ha indicado que las estudiantes distinguen el compañerismo de la amistad porque en la segunda hay una interrelación subjetiva que les permite compartir intimidades. Esto lo hacen por medio de pláticas que ocurren tanto antes de las clases como en los intersticios que se posibilitan durante la misma. Entre risas, varias estudiantes aluden a estas pláticas.

\section{Investigadora: ¿Y que las hace considerarse amigas?}

Beatriz: Creo que hemos compartido muchas intimidades en el salón. Que hemos platicado muchas cosas; y cuando una llega triste, las otras sí la perciben o cosas así. Y pues sabemos que sí podemos hablar con cualquiera que está aquí.

Eva: Y más que nada en confianza... Porque a muchos yo no les cuento mis cosas, mis intimidades. Y, ino manches, aquí nos desbocamos! ¡No puedo creer que nos platiquemos esas cosas! Y en poquito tiempo...

Beatriz: En poquito tiempo...

Investigadora: ¿Cómo qué cosas son de las que platican?

Beatriz: De los noviazgos... De todas esas cosas... Hablamos de todo...

Blanca: De Reggeton, de política...

Eva: De política...

Beatriz: A veces decimos muchas tonterías.

Blanca: Beatriz más.

Investigadora: ¿En qué momento ustedes sienten que ya se volvieron amigas?

Blanca: Cuando nos empezamos a contar las cosas que normalmente no le cuentas al que se sienta a tu lado...

Eva: pero, ¿por qué se las contamos? ¿Por qué nos empezamos a contar esas cosas?

Pilar: Por la confianza que nos inspiramos.

Blanca: Yo fui la que primero empezó a contar todo. Ustedes saben que yo...

Eva: Sí, sí...

La entrevista permitió a las estudiantes pasar un rato de diversión y de reflexión acerca de la amistad que tienen. Destacaron, entre risas, que ocupan tiempo en el aula para platicar de diversos temas, algunos públicos (como la política) y otros que se considerarían como privados o que no contarían a las compañeras (como asuntos de noviazgo y otras "intimidades"). Poder decir "tonterías" sin ser criticada, y más bien compartirlas, fue también un elemento que valoraron con jocosidad.

Durante las clases se observó que las amigas, a diferencia de las compañeras, en general se están tocando entre sí, ya sea abrazándose, tomándose de la mano o peinando y tocando el cabello de la amiga. En el aula, la cercanía con las amigas se practica por medio del hecho de tocar y ser tocada, como una necesidad psicosocial que los adolescentes tienen en su proceso de desarrollo. Al respecto, Esteban (2009) menciona que las identidades de género, los cuerpos, la identidad sexual y las relaciones amorosas se cruzan en actos básicamente corporales, mediante maneras de sentir, andar, expresarse, moverse, vestirse, adornarse, tocarse, emocionarse, atraer o ser atraída, gozar, sufrir, en interacción continua con otras personas.

Respecto al trabajo académico, las estudiantes reconocieron que también con las amigas ponían atención a sus habilidades en algunas materias, ya sea para solicitar ayuda o apoyarse en trabajos y contenidos que les resultaban difíciles.

Clara: Sí. Yo recuerdo igual en la clase de matemáticas. La vi y la ubiqué porque es muy buena para matemáticas. Entonces hacía los cálculos muy rápido y yo estaba así de "iah!, no sé". Y ella decía los resultados muy rápido. Y yo "esa niña parece calculadora".

(Risas de ambas.)

Clara: ... Y ya después en biología llegué tarde. Entonces, y ya casi todos los lugares estaban ocupados. Y pues había un lugar en su mesa, y pues le pregunté si me podía sentar con ella. Después la acompañé a su inscripción.

Sara: Ah, sí.

Clara: ... de su opción técnica y ya empezamos a platicar. Y de ahí nos juntamos diario.

Investigadora: $\mathrm{Mmm}$. ¿Ustedes identifican en qué momento se hicieron amigas?

Clara: $\mathrm{Mmmm}$.

Sara: Creo que cuando empezamos a hacer las salidas hacia Parque [centro comercial]. Clara: Ah, sí. Porque empezamos a salir hacia...

Sara: Como luego nuestro profesor de Física... Esteee... o no llegaba o llegaba un poco tarde, y ya era del grupo de "ay, ya vámonos". Pues era como "está bien, vámonos".

Clara: Eíbamos a comer a la plaza.

Sara: Y estábamos de "¿qué hacemos? Vamos a Parque", y nos íbamos a comer ahí. 
Investigadora: Ok. Entonces se iban a Parque y ahí empezaron a ser más amigas.

Sara: Sí.

En general las estudiantes entrevistadas compartieron el hecho de buscar tanto compañeras como amigas con las cuales apoyarse para asuntos académicos. Revelaron ser observadoras del comportamiento de las demás (si tomaban apuntes, si participaban en clase, cómo era su desempeño en algunas materias) con la intención de sacar provecho de esa relación. Empero, cuando se trascendía del plano académico al de la amistad, las actividades fluían hacia la diversión, tal y como Clara y Sara relatan, que decidían irse de paseo a un centro comercial cuando el docente en turno no llegaba. Ellas lograron pasar de ser compañeras a ser amigas al compartir, como se ha indicado, aspectos de confianza e intimidad, más diversiones y salidas. En ese sentido, las estudiantes practican arduamente el ser estudiantes, amigas, mujeres, jóvenes; y estas dimensiones identitarias ganan fuerza en el dinamismo de las relaciones de amistad que se extiende a lo que cada una hace fuera de la escuela. Así, por ejemplo, entre ellas saben lo que les acontece y se dan consejos.

Ana: Ajá, incluso en el transporte ella llegaba y nos contaba cómo es el recorrido de su casa a la escuela... Es como "es que hoy una señora no me dejaba pasar". Y yo, así de "¿por qué no le pides permiso? Tienes que decirle. No, no te puedes quedar callada". O sea, si veía un señor, le daba como mucho miedo...

Flor: Le daba como mucho miedo.

Ana: Le decíamos "ino!, tienes que mostrar seguridad, porque si no te iba a hacer nada, te va a hacer algo", ¿no? Siempre le decimos cómo, y ya al final nos decía "si quieren me voy sola".

Flor: Ajá, pues es que ella no sabía de irse en el transporte público; entonces, ya cuando me conoce a mí, pues como vivimos muy cerca, pues ya yo le enseñé: "mira, te pones aquí, ponte segura. Si te pasa esto, puedes tomar tal combi o asi". Entonces, ya igual le enseñé... $Y$ ahora tiene horario mixto y ya se tiene que ir sola... Y dice "es que ya me sé atravesar o así".

(Risas.)

Ana: ... Porque...

Flor: Le daba mucho miedo...
Ana: Porque para atravesar la calle era como de "iahhh!".

Flor: Le daba mucho miedo..., pero pues ahora ya como que la veo muy segura. Y no pues de "ya me pude atravesar".

Se ha mencionado que, de acuerdo con Martínez (2013), en las relaciones de amistad los y las estudiantes desarrollan habilidades complejas, tal y como Flor y Ana relatan de otra amiga a la que le enseñaron a cruzar la calle, pero también la alentaron a usar su voz para defenderse en el transporte público. Quizá los padres y madres dan por supuesto que este tipo de habilidades ya las tienen sus hijas, pero son las amigas con más experiencia quienes les enseñan cómo lograrlas y obtener seguridad. Ellas delimitaron bien el campo de impacto que buscaban tener en su amiga: que se sintiera segura, que supiera cómo hablar, que tuviera habilidad para una acción compleja (como cruzar una calle), información de rutas de transporte, y sobre todo estuvieron atentas a identificar cuándo la otra chica ya se sentía tranquila.

Ana y Flor también comentaron cómo se apoyaban entre amigas para detener acciones que consideraban abuso por parte de una compañera de grupo.

Ana: Bueno, a mí en primer semestre había una chica que llegaba y me tocaba las pompis. $Y$ así de "oye, qué te pasa". Y a nuestra otra compañera, llegaba, la otra chica y la tocaba. Oye "dile que no te gusta, que no te haga eso". $Y$ ella "no es que...". O sea, no se defendía; pero así que yo me haya dedicado a pelear con alguien, no.

Flor: No, a mí que no me agarre. A mí nunca me ha gustado eso.

Investigadora: ¿Qué te hizo decirle?

Ana: Es que, por ejemplo, yo le dije a Isa... porque una compañera si pasaba y le tocaba...

Flor: La nalgueaba...

Ana: Ajá. Y yo "por qué no le dices nada". Y ella "es que...". O sea, no se defendía, y así como que [yo le decía] "pues dile algo, porque si a ti te molesta, pues debes expresarlo para que lo deje de hacer".

Flor: Y aparte la chica lo hacía en forma de... No sé... No sé... Así de morbo... La veía así, como... No sé, sentía así, indefensa a Isabel. Y le decía "pues dile algo". Yo la pasaba así para el otro lado para que no la agarrara. 


\section{Ana: Ya cuando la veíamos que venía, nosotras nos poníamos al lado para que a ella no la to- cara. A nosotras no nos pegaba; sólo a ella.}

Acerca de esta situación, retomamos a Cabnal (2018) quien, desde el feminismo comunitario usa la noción de "acuerpamiento o acuerpar", y lo define como la acción personal y colectiva de los cuerpos indignados ante injusticias que viven otros cuerpos. En esta acción de "acuerpar" las participantes resisten y actúan contra las múltiples opresiones patriarcales, colonialistas, racistas y capitalistas. Para el caso de las alumnas amigas, identificamos que generan interacciones afectivas y espirituales que ofrecen cercanía y empuje para participar en situaciones complejas en las que se sienten vulnerables; por ejemplo, juntar sus cuerpos para impedir que una compañera incómoda toque los glúteos de la amiga que no sabe defenderse, ir a hacer un trámite escolar, ir a clase con un profesor con quien se sienten incómodas, acompañarse en el camino a la casa o la escuela, y mantenerse juntas o ubicables en las fiestas, entre otras situaciones.

En el $\mathrm{CCH}$ elegir y sostener a las amigas implica una labor diaria. Dado que el alumnado es cambiado de grupo de un semestre a otro, las amistades que se lograron en algún grupo se mantienen en actividades fuera del aula o de la escuela, entre clases o en tiempos no escolares. Al final del recorrido por los distintos semestres escolares, las estudiantes tienen amigas que lograron en diferentes momentos, algunas más cercanas, otras a las que ven con menos frecuencia, pero con las que consiguieron establecer lazos de afecto.

En síntesis, las estudiantes otorgaron un alto valor a las amistades en la escuela. Dijeron haber sido selectivas para identificar quién podía ser su amiga en función de diversas similitudes para, con el paso del tiempo, establecer lazos de intimidad, confianza y apoyo. Las actividades desplegadas para sostener prácticas de amistad fluyeron antes, durante y después de las clases, en tiempos de ocio y diversión dentro y fuera de la escuela. Entre risas y bromas compartidas usaron el tiempo de la entrevista para recordar sus historias de amistad, momentos clave para sus vidas como estudiantes y en sus relaciones de sororidad expresadas en el apoyo que compartieron.

\section{Discusión}

El presente trabajo tuvo como objetivo caracterizar y analizar las prácticas de compañerismo y de amistad en las que mujeres estudiantes de $\mathrm{CCH}$ que participan en diferentes contextos de práctica, dentro y fuera de la escuela. Fue posible identificar que ambos modos de relación interpersonal son importantes en el día a día escolar, aunque la amistad tiene un carácter de intimidad y alta valoración para ellas. Tanto por medio de las compañeras como de las amigas, las estudiantes logran metas en la escuela, como pasar tiempo juntas, apoyarse para hacer actividades académicas, platicar y participar en las actividades escolares.

Elegir quién puede ser una compañera de clase es una tarea que se despliega en el aula desde que se ingresa a la misma, se localiza un lugar vacío para sentarse y cada estudiante mujer monitorea a las demás para identificar la posibilidad de encontrar puntos en común. Se logra ser compañeras cuando coinciden en una actividad compartida, pero se tiene la claridad de que no avanzarán más allá de la misma. Por el contrario, se avanza a la amistad cuando en el sondeo de las similitudes y diferencias con las compañeras cada estudiante identifica que pueden tender puentes de intersubjetividad.

Esto favorece establecer prácticas que se caracterizan por compartir aspectos emocionales, apoyarse o ayudarse, fomentar el uso de sus voces para defenderse, cooperar entre ellas en lugar de competir, darse consejos para la toma de decisiones sin imponerse, valorarse en lugar de descalificarse, protegerse, acompañarse, comprenderse aunque no estén de acuerdo, y reír, reír mucho cada día, es decir, participar en relaciones que podemos interpretar como sororales.

\section{Conclusiones}

En la investigación fue importante desmenuzar las actividades en que se concretaban las prácticas de compañerismo y amistad de las estudiantes en el $\mathrm{CCH}$, porque en general la investigación que citamos inicialmente no considera el género como una categoría de análisis para comprender ambos fenómenos (Ibarra y Jacobo, 2017; Moreira, Sánchez y Mirón, 2010; Ramírez, 2014). Además, algunos de los estudios citados (Casper y Card, 2010; Moreira, Sánchez y Mirón, 2010) se apoyan en cuestionarios o escalas de valoración de los distintos componentes de las relaciones de amistad. Al observar a las estudiantes en el $\mathrm{CCH}$ se comprendió que sus prácticas de compañerismo y amistad responden tanto a la organización que la escuela delimita (por ejemplo, cambiar al alumnado de grupo en cada semestre), como de las posturas personales y esfuerzos de las estudiantes por preservar a sus amistades. Ser compañeras se apega más a actividades escolares, mientras que ser amigas se explaya a otros ámbitos de participación dentro y fuera de la escuela. 
Las compañeras y las amigas permiten a las mujeres estudiantes aprender diversas habilidades psicosociales, ya sea para organizarse para hacer tareas, hablar con el profesorado, exponer algún material en clase o lo que parecería simple, pero no lo es: estar acompañadas en el aula. Se ha demostrado cómo en las relaciones de amistad entre varones predominan encuentros más bien grupales, poco íntimos y con carácter instrumental (Mathur y Berndt, 2006), mientras que las amistades entre mujeres favorecen una amplia gama de oportunidades de aprendizaje que las propias estudiantes señalaron: tener alguien cercano e íntimo en quien confiar, enseñarse unas a otras a maquillarse, a cruzar una calle, a defenderse, acuerparse para proteger a la amiga más vulnerable. En la amistad entre mujeres hay un componente de empatía que se puede denominar de género, que les permite reconocerse como iguales y distintas para enfrentar juntas algunas manifestaciones de sexismo o acoso en la escuela y en las actividades de sociabilidad vinculadas a ella (asistir a museos o teatros, ir a tomar cerveza al salir de clases, etcétera) que comprenden desde su posiciones como estudiantes mujeres.

Al estar en la escuela las mujeres practican no sólo su identidad como estudiantes, sino también ser mujeres, amigas, jóvenes, compañeras. Este es un trabajo arduo porque tienen que estar atentas a las señales de similitud con las otras, a la aceptación común, a la diversión que se acepta o se rechaza. Quizás en la secundaria cada estudiante mujer tuvo a sus mejores amigas en el mismo grupo, lo cual facilitó un poco la tarea de mantener esos vínculos. Pero en el bachillerato, sobre todo en el $\mathrm{CCH}$, aprenden a buscar en otros espacios, tiempos y maneras de encontrarse, de modo que las amistades son relaciones no sólo elegidas sino también sostenidas a lo largo del tiempo.

De esta manera podría investigarse cómo las estudiantes viven y significan cada una de las dimensiones que las configuran más allá del género, del sexo y de la edad, y que influyen en las prácticas relacionales entre ellas: la condición socioeconómica, los rasgos corporales, la condición laboral y las creencias religiosas, entre otros aspectos sociales que influyen en el inicio y sostenimiento de relaciones de compañerismo y amistad entre ellas en la escuela.

Se sabe que las prácticas para construirse y construir significados como mujeres son distintas a las prácticas en que participan los estudiantes hombres que regularmente no se enfrentan a la violencia de género como las estudiantes mujeres en el ámbito escolar, aunque en ambos casos las prácticas normativas de feminidad y masculinidad (Tomasini, 2015b) siguen presentes con fuerza en los contextos escolares, y es necesario su análisis de camino a la transformación social.

Durante la investigación los estudiantes hombres se mostraron interesados en participar en las entrevistas, por lo que se sugiere — para futuras investigacionespromover y concretar su participación para el análisis de los aspectos de género en las relaciones prácticas en el bachillerato, lo que permitiría una comprensión de las experiencias de compañerismo y amistad nutrida y profunda en el papel del género en las prácticas relaciones no sólo entre las estudiantes mujeres sino también entre los estudiante hombres y entre chicos y chicas.

Al respecto, la investigación plantea nuevas interrogantes, porque algunas de las estudiantes que participaron en las entrevistas individuales refirieron tener más amigos hombres en el bachillerato que amigas mujeres. En las entrevistas grupales algunas estudiantes comentaron que forman parte de grupos de amistades más grandes donde hay igual número de estudiantes hombres o en los que ellas son minoría o "las únicas chicas" de esos grupos de amistades.

Sostenemos que es necesario continuar aprendiendo de los esfuerzos de las estudiantes para respetarse, apoyarse, reconocerse y delimitar espacios de actuación mediante sus prácticas de compañerismo y de amistad, para cuestionar y desmontar la enemistad histórica entre las mujeres en la escuela y los otros ámbitos de la vida social. Por medio de las prácticas sororales que incluyen a las de affidamento (reconocimiento y apoyo de autoridad femenina) y acuerpamiento (acompañamiento corporal) es posible fortalecer comportamientos para evitar o contrarrestar violencias que atentan contra su condición de género y como estudiantes jóvenes en el bachillerato.

\section{Referencias}

Bohórquez, L., \& Rodríguez, D. (2014). Percepción de amistad en adolescentes: el papel de las redes sociales. Revista Colombiana de Psicología, 23(2), 325-338.

Bruner, J. (1990). Actos de significado. Madrid: Alianza Editorial. Cabnal, L. (2018). Participación en foro en línea. Internacionalisme Solidaritat Feminismes. Recuperado: 23 de febrero de 2019 de https://suds.cat/es/experiencias/lorena-cabnalfeminista-comunitaria/

Casper, D., \& Card, N. (2010). "We were best friends, but...": Two studies of antipathetic relationships emergenig from broken friendships. Journal of Adolescent Research, 25(4), 499-526.

Cigarini, L. (2000). El affidamento. En: Mujeres 8. Mediar para reconocer otros mundos en este mundo. España: Universidad Jaume I. Fondo Social Europeo. Proyecto NOW. 29-38.

Dreier, O. (1997). Personal trajectories of participation across contexts of social practice. In: Subjectivity and Social 
Practice. Center for Healt, Humanity and Culture: University of Aarhus, Denmark.

Esteban, G. M. (2011). La geografía vital y psicológica de la interculturalidad. Cuadernos interculturales. Año 9, No. 16. Primer Semestre. 33-44.

Esteban, G. M. L. (2009). Identidades de género, feminismo, sexualidad y amor: los cuerpos como agentes. Política y sociedad, 46(1 y 2), 27-41.

Fontana, A., \& Frey, J. H. (2015). La entrevista. De una posición neutral al compromiso político. En: Denzin, N. y Lincoln, Y. Manual de investigación cualitativa. Métodos de recolección y análisis de datos. Vol. IV. México: Gedisa. 140-202.

Ibarra, E., \& Jacobo, H. (2017). La evolución de la concepción de amistad a través del concepto de compañero y amigo, y la trayectoria del autoconcepto social durante la adolescencia. Revista de Educación y Desarrollo, 42, 13-23, Recuperado: 23 de febrero de http://www.cucs.udg.mx/ revistas/edu_desarrollo/anteriores/42/42_Ibarra.pdf

Gaviola, E. (2015). Apuntes sobre la amistad política de las mujeres. En: A nuestras amigas. Sobre la amistad política de las mujeres. Argentina: Pensaré Cartoneras. Recuperado: 25 de agosto de 2018 de https://issuu.com/ pensarecartoneras/docs/a_nuestras_amigas

Gibbs, G. (2012). El análisis de datos cualitativos en investigación cualitativa. España: Morata.

Grijalva, O. (2011). La diversión y el trabajo académico como fuentes de las identificaciones de los jóvenes en sus grupos de pares. CPU-e. Revista de Investigación Educativa, recuperado 11 de Septiembre de 2018, de http://www.redalyc.org/html/2831/283121721003/.

Guzmán, V. C. (2014). Polos epistemológicos: uso y construcción de teoría en investigación cualitativa en educación. Magis. Revista Internacional de Investigación en Educación, 7(14), 15-28.

Hernández, J. (2012). Las relaciones afectivas y los procesos de subjetivación y formación de la identidad en el bachillerato. Perfiles educativos, 34(135), 116-131. Recuperado: 23 de agosto de 2018, de http://www. scielo.org. $\mathrm{mx} /$ scielo.php?script=sci_arttext\&pid=S018526982012000100008\&lng=es\&tlng=es

Hernández, R., Fernández, C. C., \& Baptista, L. P. (2010). “Diseños del proceso de investigación cualitativa". En: Metodología de la investigación. México: McGraw-Hill.

Korol, C. (2015). Feminismo compañero de las feministas compañeras. En: A nuestras amigas. Sobre la amistad política de las mujeres. Argentina: Pensaré Cartoneras. Recuperado: 25 de agosto de 2018, de https://issuu.com/ pensarecartoneras/docs/a_nuestras_amigas

Lagarde, M. (2012). El feminismo en mi vida. Hitos, claves y topías (pp. 461-492). México: Instituto de las Mujeres de la Ciudad de México.

López, B. C., Rivera, A. S., \& Reyes, L. I. (2007). Inventario de estrategias de mantenimiento de la amistad. Revista Iberoamericana de Diagnóstico y Evaluación, 23, 23-39.
Martínez, B. (2013). El mundo social del adolescente: amistades y pareja, En E. Estévez (coord.), Los problemas de la adolescencia: respuestas y sugerencias para padres y educadores. Madrid: Síntesis. 71-96.

Martínez, A. M. (2012). Feminismo: un uso estratégico del vocabulario. En M. Belausteguigoitia y R. Lozano (coords). Pedagogías en espiral. Experiencias y prácticas (pp. 111-121). México: Universidad Nacional Autónoma de México.

Martínez, M. (2011). Intersubjetividad y teoría de la mente. Psicología del Desarrollo, 1(11), 9-28.

Mathur, R., \& Berndt, T. (2006). Relations of friend's activities to friendship quality. Journal of Early Adolescence, 26(3), 365388.

Mejía, H. J. M., \& Weiss, E. (2011). La violencia entre estudiantes de secundaria. Revista Mexicana de Investigación Educativa, 16(49), 545-570.

Moreira, V., Sánchez, A., \& Mirón, L. (2010). El grupo de amigos en la adolescencia. Relación entre afecto, conflicto y conducta desviada. Boletín de Psicología, 100, 7-21.

Pantoja, L. (2013). La amistad entre pares: análisis de las relaciones de género en un bachillerato y su influencia en actividades académicas. Tesis para obtener el grado de maestra en Desarrollo Educativo. México: UPN.

Paulín, H. L. (2015). "Ganarse el respeto". Un análisis de los conflictos de la sociabilidad juvenil en la escuela secundaria. Revista Mexicana de Investigación Educativa, 20(67), 1105-1130.

Ramírez, R. (2014). "Amigos, simplemente amigos": intimidad entre hombres y masculinidad. En: T. Rocha e I. Lozano (2014). Debates y reflexiones en torno a las masculinidades: Analizando los caminos hacia la igualdad de género. México: Universidad Nacional Autónoma de México. 253-277.

Tomasini, M. (2015a). Feminidades juveniles, cuerpos y producciones estéticas en la escuela secundaria. Revista Interamericana de Educación, V(68), 117-135.

Tomasini, M. (2015b). Peleas en joda, peleas chiquitas, peleas en serio: la gestión de la vida social en la escuela. En: D. Miguez, P. Gallo y M. Tomasini, Las dinámicas de la conflictividad escolar. Procesos y casos en la Argentina reciente. Argentina: Editores Miño y Dávila.

Tomasini, M. (2014). Las chicas malas. Significaciones sobre las agresiones físicas en las peleas entre jóvenes. Conferencia. 3er. Congreso Género y sociedad. "Voces, cuerpos y derechos en disputa". Argentina: Universidad de Córdoba. Recuperado: 23 de febrero de 2019, de: http://conferencias.unc.edu.ar/index.php/gyc/3gyc/ paper/viewFile/2582/662

Tomasini, M., \& Bertarelli, P. (2014). Devenir mujeres en la escuela. Apuntes críticos sobre las identidades de género. Quaderns de Psicología, 1(16), 188-199.

Fondo de las Naciones Unidas para la Infancia (UNICEF) (2013). Superando el adultocentrismo. Chile: UNICEF. Recuperado: 25 de agosto de 2018, de: http://unicef. cl/web/wp-content/uploads/2012/12/UNICEF-04SuperandoelAdultocentrismo.pdf 


\section{Meta-Análisis del Artículo}




\section{Dimensión Cuantitativa}

\section{Perfil de Evaluación entre pares}
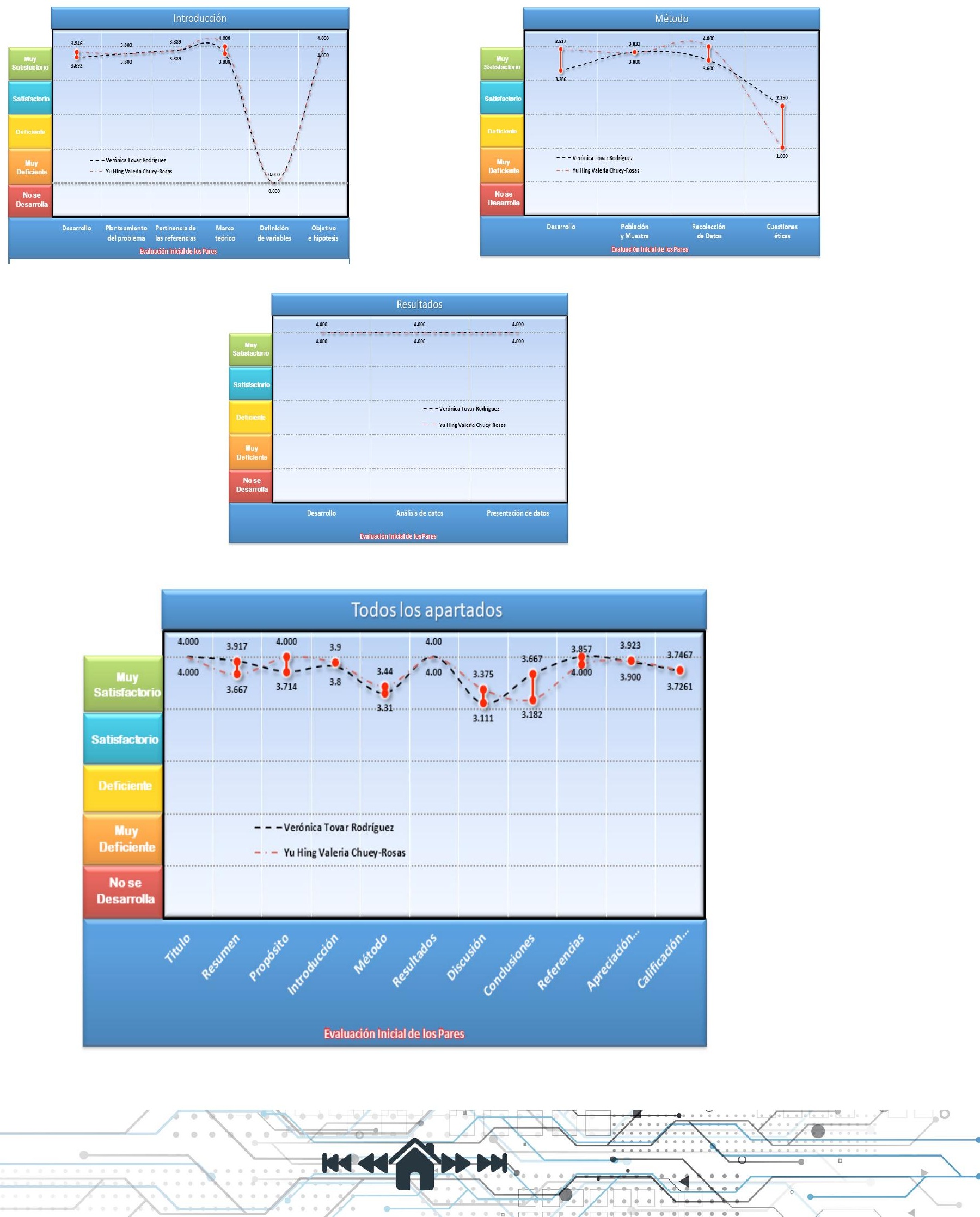


\section{Índice de Concordancia}

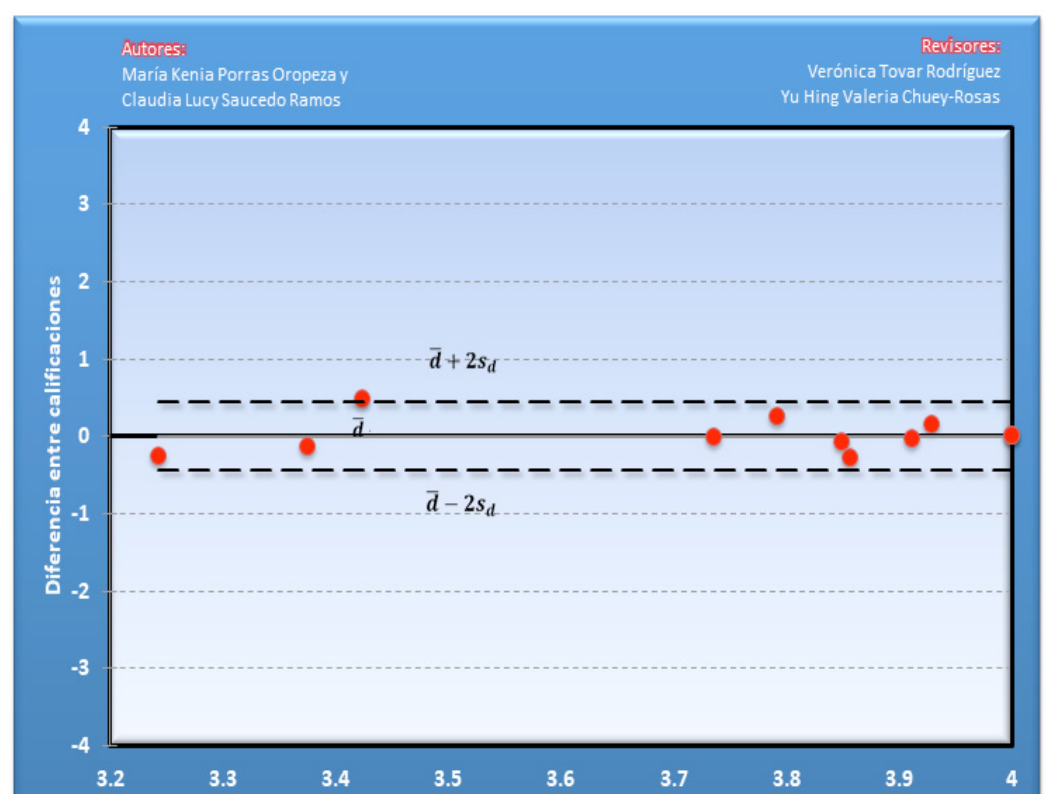

Índice de Acuerdo

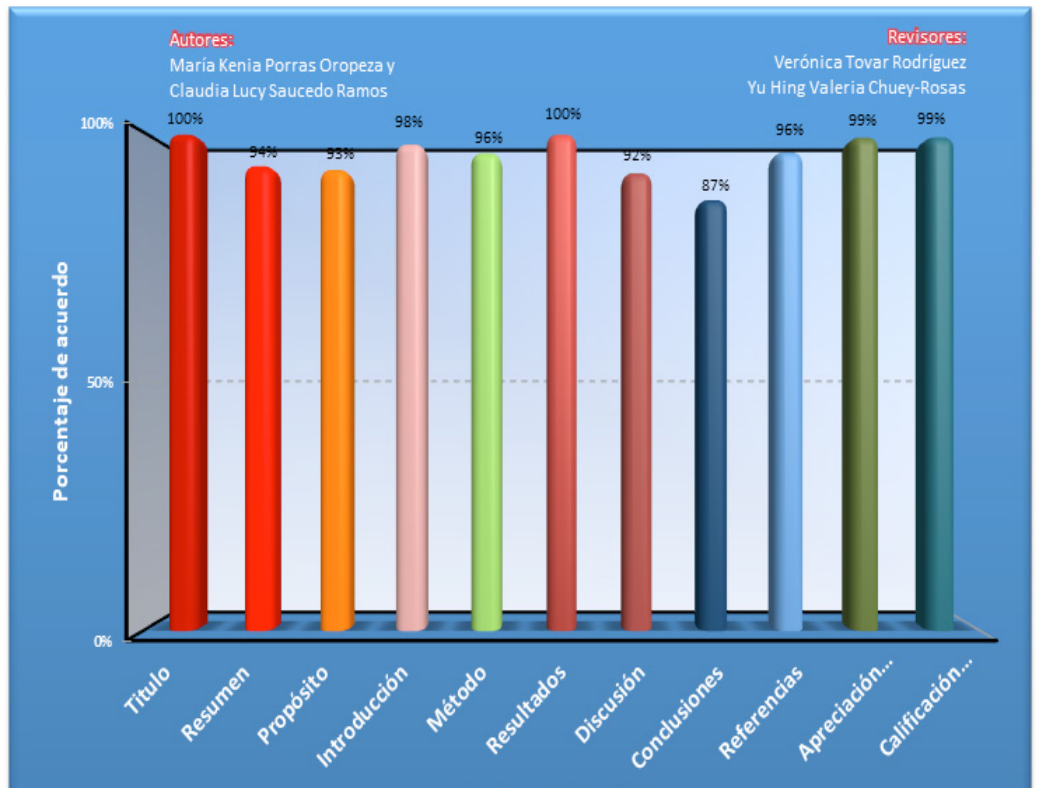


Dimensión Cualitativa

\begin{tabular}{|c|c|}
\hline Revisor 1 & Revisor 2 \\
\hline Verónica Tovar Rodríguez & Yu Hing Valeria Chuey-Rosas \\
\hline
\end{tabular}

\section{Título/Autoría}

No tengo sugerencias para mejorar el título, es adecuado. El título es adecuado.

\section{Resumen}

El resumen me parece suficientemente explicativo, no tendría sugerencias para mejorarlo

Aunque desde el inicio se explica qué se analizó, sería importante señalar cuál es la importancia de ese análisis, ¿por qué se realizó?. El resumen contiene más de 150 palabras. En las palabras clave, como sugerencia, se podría utilizar la palabra bachillerato en vez de escuela.

\section{Próposito del Estudio}

Considero que algo que podría enfatizar los hallazgos del estudio es destacar la elección del paradigma cualitativo de investigación y su pertinencia para responder las inquietudes planteadas en la investigación
Como sugerencia, sería pertinente resaltar la importancia del estudio, que aunque se señala a lo largo de la introducción y antes del método, se podría utilizar otro orden en las palabras, por ejemplo, se señala: Lo anterior nos permitirá, hacia la conclusión, analizar los componentes de la amistad y el compañerismo entre mujeres en la escuela preparatoria, y su importancia para el desarrollo psicosocial de las estudiantes. Sugerencia: Dada la importancia del desarrollo psicosocial de las estudiantes se analizará los componentes de la amistad y el compañerismo entre mujeres en la escuela preparatoria.

\section{Introducción}

Considero que se podría elaborar aparte en un apartado más, un breve abordaje sobre el marco teórico y epistémico bajo los cuales se inscribe la investigación, ya que el primero es mencionado brevemente y el segundo no esta enunciado y al ser una investigación de corte cualitativo no se enfatiza la importancia de considerar la experiencia desde la voz de los sujetos y el motivo de la elección de dicho paradigma epistémico.
Sería importante resaltar el por qué del estudio, resaltar su relevancia. También sería pertinente señalar cuáles son los vacíos de información respecto al tema y por lo tanto, resaltar la importancia del mismo. 


\begin{tabular}{|c|c|}
\hline Revisor 1 & Revisor 2 \\
\hline \multicolumn{2}{|c|}{ Método } \\
\hline $\begin{array}{l}\text { Partiendo de que se trata de un estudio de corte cualitati- } \\
\text { vo, que empleó entre sus estrategias metodológicas la ob- } \\
\text { servación participante y la entrevista semi-estructurada } \\
\text { considero que hace falta una mayor descripción del pro- } \\
\text { ceso del trabajo de campo, sobre todo del contexto social, } \\
\text { cultural y educativo en el que se desenvuelve la investi- } \\
\text { gación. Por otro lado no hay datos en el artículo que nos } \\
\text { permitan a los lectores hacernos una idea del tratamiento } \\
\text { ético de la invitación y participación de las jóvenes en la } \\
\text { investigación así como de los cuidados que la investigado- } \\
\text { ra llevó a cabo sobre el cuidado de su identidad. }\end{array}$ & $\begin{array}{l}\text { En la sección Participantes, sería pertinente señalar que } \\
\text { se asegurará el anonimato y confidencialidad de los parti- } \\
\text { cipantes en el estudio, así como señalar que se cambiarán } \\
\text { los nombres de los participantes, para seguir garantizando } \\
\text { dichas cuestiones. }\end{array}$ \\
\hline \multicolumn{2}{|c|}{ Resultados } \\
\hline $\begin{array}{l}\text { Los resultados me parecen excelentes, la combinación de } \\
\text { las tablas con los extractos de las entrevistas permite al lec- } \\
\text { tor hacerse una idea clara de lo que se encontró }\end{array}$ & $\begin{array}{l}\text { Las tablas utilizadas complementan visual y adecuada- } \\
\text { mente la información. }\end{array}$ \\
\hline \multicolumn{2}{|c|}{ Discusión } \\
\hline $\begin{array}{l}\text { Considero que la discusión podría complejizarse ha- } \\
\text { blando de aquellos datos que se encontraron que no } \\
\text { necesariamente se corresponden a la teoría o estudios } \\
\text { revisados y complementando con nuevas preguntas } \\
\text { que se abren a partir del análisis de los datos }\end{array}$ & $\begin{array}{l}\text { Sería pertinente señalar cuáles fueron as limitaciones del } \\
\text { estudio. }\end{array}$ \\
\hline \multicolumn{2}{|c|}{ Conclusiones } \\
\hline $\begin{array}{l}\text { Las conclusiones me parecen contundentes, y abren } \\
\text { temas que podrían profundizarse como por ejemplo: } \\
\text { "Al estar en la escuela las mujeres practican no sólo su } \\
\text { identidad como estudiantes, sino también ser mujeres, } \\
\text { amigas, jóvenes, compañeras. Este es un trabajo arduo } \\
\text { porque tienen que estar atentas a las señales de simili- } \\
\text { tud con las otras, a la aceptación común, a la diversión } \\
\text { que se acepta o se rechaza" (pág.31) }\end{array}$ & $\begin{array}{l}\text { Es importante señalar las investigaciones que se sugieren } \\
\text { después del estudio, así como las contribuciones y reper- } \\
\text { cusiones generadas. Asimismo, agregar cuáles fueron las } \\
\text { deficiencias y qué se sugiere para enfrentarlas. }\end{array}$ \\
\hline \multicolumn{2}{|c|}{ Referencias } \\
\hline No hay comentarios & Faltan dos fechas de recuperación. \\
\hline
\end{tabular}


